\title{
IMPROVEMENT OF THE REALISATION OF THE MASS SCALE
}

\author{
Z. Zelenka ${ }^{1}$, S. Alisic ${ }^{2}$, B. Stoilkovska ${ }^{3}$, R. Hanrahan ${ }^{4}$, I. Kolozinsky ${ }^{5}$, G. Popa ${ }^{6}$, D. Pantić 7 , V. Dikov ${ }^{8}$, J. Zůda ${ }^{9}$, \\ M. Coenegrachts ${ }^{10}$, A. Malengo ${ }^{11}$ \\ ${ }^{1}$ BEV Bundesamt für Eich- und Vermessungswesen PTP Physikalisch-Technischer Prüfdienst, Austria, \\ zoltan.zelenka@bev.gv.at \\ ${ }^{2}$ Institute of Metrology of Bosnia and Herzegovina, Bosnia and Herzegovina, sejla.alisic@met.gov.ba \\ ${ }^{3}$ Ministry of Economy - Bureau of Metrology, North Macedonia, bianka.stoilkovska@bom.gov.mk \\ ${ }^{4}$ NSAI National Metrology Laboratory, Ireland, rory.hanrahan@ nsai.ie \\ ${ }^{5}$ National Scientific Centre Institute of Metrology, Ukraine, iren_kolozinsky@ukr.net \\ ${ }^{6}$ BRML Biroul Roman de Metrologie Legala, INM Institutul National de Metrologie, Romania, george.popa@inm.ro \\ ${ }^{7}$ Ministarstvo privrede - Direkcija za mere i dragocene metale, Serbia, pantic@dmdm.rs \\ ${ }^{8}$ Bulgarian Institute of Metrology, Bulgaria, v.dikov@ bim.government.bg \\ ${ }^{9}$ Cesky Metrologicky Institut, Czech Republic, jzuda@cmi.cz \\ ${ }^{10}$ FPS Economy, Metrology Division - National Standards (SMD - ENS), Belgium, \\ mieke.coenegrachts@economie.fgov.be \\ ${ }^{11}$ Istituto Nazionale di Ricerca Metrologica, Italy, a.malengo@inrim.it
}

\begin{abstract}
:
The project 19RPT02 "Improvement of the realisation of the mass scale" (EMPIR [1] Call 2019 - Energy, Environment, Normative and Research Potential) has just started.

Its aim is to improve the quality of one of the most important tasks in mass metrology, the realisation of the mass scale. After the new definition of the kilogram this technique is getting more important.
\end{abstract}

Keywords: mass realisation; kilogram; multiples and sub-multiples; subdivision and multiplication; OIML R111 [2]

\section{INTRODUCTION}

The overall aim is to improve calibration methods for the realisation of the mass scale.

In the past, two EURAMET projects have tried to address the issues related to the realisation of the mass scale, but due to the complexity of the work, were unable to fully satisfy the requirements.

The project includes the development of the design of the measurements; the improvement of the applied mathematical methods; provision of realistic algorithms and software tools for the realisation of the mass scale and the respective uncertainties. Furthermore, a draft of a guide for the dissemination of the mass unit with respect to the new definition of kilogram is among the goals.

The project partners are: CMI, Czech Republic; BEV-PTP, Austria; SMD, Belgium; IMBiH, Bosnia and Herzegovina; BIM, Bulgaria; NSAI, Ireland;
INRIM, Italy; BRML, Romania; DMDM, Serbia; ME-BoM, North Macedonia and NSC-IM, Ukraine.

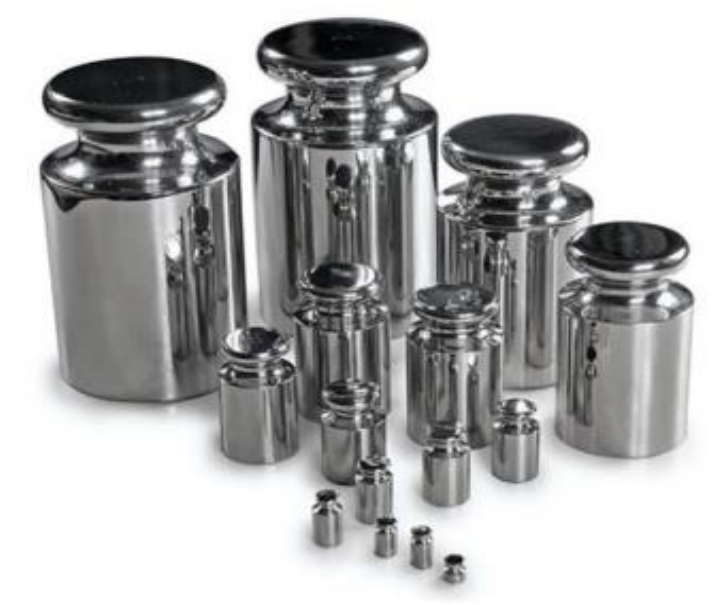

Figure 1: Some weights to be calibrated against limited number of mass standards

\section{IMPORTANCE OF THE WORK}

In the last years the mass metrology community was focusing on the definition and realisation of the unit of mass, the kilogram [3, 4].

On the other hand the other big challenge is the calibration of the other nominal values against a single mass standard was somewhat overlooked. A comprehensive analysis of the existing dissemination methods is not yet available. The used methods of dissemination of mass unit with some exceptions are so far based on a limited number of sources such as procedure developed and published by PTB [5, 6]. Due to several factors such 
as involvement of robotic mass comparators, dimensional limitations of the inner chambers or weighing pans of the mass comparators or different composition of the weighing set, the methods shall be reshaped to the actual laboratory needs. Some available publications are covering parts of the task [7 - 14].

Despite the very recent new SI, usually the $1 \mathrm{~kg}$ mass standard is still used as starting point of the dissemination process, as it was at the time when the definition of the kilogram was based on the international prototype.

One of the outcomes of the new definition is that the uncertainty of the calibration of the one kilogram mass standards is increased. It forces a lot of national metrology institutes to enlarge their calibration measurement capabilities [15]. The most important scientific result of the proposed improvement in subdivision and multiplication techniques is that it could play an important role in preventing many National Metrology Institutes (NMIs) from being forced to increase their Calibration and Measurement Capabilities [15].

The specific objectives of the project are:

a) to analyse the methods for realisation and dissemination of the mass scale including the impact from the recent redefinition of the kilogram; to create an appropriate methodology in order to optimise for different technical requirements and parameters (e.g. robustness, effectiveness, small uncertainty, properties of different weighing instruments, different types of weight sets, number of control weights or standards).

b) to develop and implement calibration methods to realise, improve and maintain the mass scale.

c) to develop advanced mathematical and statistical tools and software solutions to calculate the results from mass measurements and to evaluate the associated uncertainties (including correlations between standards and measurements and handling of outliers).

d) to draft a EURAMET guideline for the realisation of the mass scale.

e) for each participant, to develop an individual long-term strategy.

\section{AIMED SCIENTIFIC RESULTS}

Improved designs of the measurements with guidance for choosing an appropriate design will be produced. It includes optimisation for robustness, effectiveness, uncertainty, taking into account the properties of different weighing instruments, different types of set of weights, the number of control weights and mass standards.

Second scientific results would be a reduction of the uncertainties via better mathematical methods. Currently used mathematical solutions are usually limited to ordinary or weighted least squares methods. Generally, these methods do not allow the use of multiple mass standards as input to the disseminations. This is probably the biggest opportunity to improve the realisation of the mass scale, because the different realisation of mass unit delivers calibration of different nominal values. Recalling that in the past the one kilogram was the solely the starting point of the realisation of the mass scale. Nowadays with Kibble balances, the mass of weights with a wider range of nominal values can be determined (e.g. $50 \mathrm{~g}$ to $1 \mathrm{~kg}$ ) while using other techniques (e.g. capacitive, electrostatic) small mass standards (e.g. $10 \mathrm{mg}$ to $1 \mathrm{~g}$ ) can be realised. All these calibrated mass standards shall be included as input into the calculation of the mass scale in order to reduce the uncertainties.

\section{SUMMARY}

This article is to bring into attention the scientific potential of the EMPIR project "Realmass", which is aiming the improvement of one of the most important techniques in mass metrology, the realisation of the mass scale.

\section{ACKNOWLEDGMENT}

This project has received funding from the EMPIR programme co-financed by the Participating States and from the European Union's Horizon 2020 research and innovation programme.

\section{REFERENCES}

[1] European Metrology Programme for Innovation and Research (EMPIR), EURAMET. Online [accessed 20200817]:

https://www.euramet.org/researchinnovation/research-empir/

[2] OIML Recommendation R 111, Weights of classes $\mathrm{E}_{1}, \mathrm{E}_{2}, \mathrm{~F}_{1}, \mathrm{~F}_{2}, \mathrm{M}_{1}, \mathrm{M}_{1-2}, \mathrm{M}_{2}, \mathrm{M}_{2-3}$ and $\mathrm{M}_{3}$.

[3] EURAMET EMRP JRP SIB05 NewKILO Developing a Practical Means of Disseminating the New Kilogram.

[4] EURAMET EMRP JRP SIB03 kNOW Realisation of the awaited definition of the kilogram - resolving the discrepancies.

[5] M. Borys, R. Schwartz, A. Reichmuth, R. Nater, Fundamentals of Mass Determination, Springer, 2012.

[6] R. Schwartz, M. Borys, F. Scholz, Guide to Mass Determination with High Accuracy, PhysikalischTechnische Bundesanstalt Braunschweig and Berlin, Wirtschaftsverlag NW, Bremerhaven, 2007.

[7] W. Bich, "Variances, Covariances and Restraints in Mass Metrology", Metrologia vol. 27, no. 3, pp. 111-116, 1990.

[8] Z. Zelenka, "Dissemination of the unit of mass in a fully automatic mass laboratory using subdivision", Proc. XIX IMEKO World Congress, Lisbon, Portugal, 6 - 11 September 2009. Online [accessed 
20200817]:

http://www.imeko2009.it.pt/Papers/FP_123.pdf?w b48617274=736ACBAB

[9] Z. Zelenka, "Improvements on dissemination of the unit of mass in BEV", Proc. XX IMEKO World Congress, Busan, Republic of Korea, 9-14 September 2012. Online [accessed 20200817]:

https://www.imeko.org/publications/wc2012/IMEKO-WC-2012-TC3-P7.pdf

[10] Z. Zelenka, "Robust subdivision for the dissemination of the unit of mass", Proc. XXI IMEKO World Congress, Prague, Czech Republic, 30 August - 4 September 2015. Online [accessed 20200817]:

https://www.imeko.org/publications/wc2015/IMEKO-WC-2015-TC3-095.pdf

[11] Z. Zelenka, "Estimation technique of the mass of drifting mass standards", J. Phys.: Conf. Ser. vol 1065, 042030, 2018. Online [accessed 20200817]:

http://iopscience.iop.org/article/10.1088/17426596/1065/4/042030
[12] M. Grum, M. Oblak, I. Bajsić, M. Perman, "Subdivision of the unit of mass using weight support plates", Proc. XVII IMEKO World Congress, Dubrovnik, Croatia, 22 - 27 June 2003. Online [accessed 20200817]:

https://www.imeko.org/publications/wc2003/PWC-2003-TC3-034.pdf

[13] A. Vâlcu, "Improvement of the calibration process for Class $\mathrm{E}_{1}$ weights using an adaptive subdivision method", $4^{\text {th }}$ Int. Conf. Adaptive \& Self-Adaptive Systems \& Applications, 2012.

[14] A. Vâlcu, D. Dinu, "Subdivision method applied for OIML weights using an automatic comparator", Proc. XIX IMEKO World Congress, Lisbon, Portugal, 6-11 September 2009. Online [accessed 20200817]: http://www.imeko2009.it.pt/Papers/FP 149.pdf

[15] Calibration and Measurement Capabilities, available from the BIPM key comparison database. Online [accessed 20200817]: http://kcdb.bipm.org/appendixC/ 